\title{
Web crippling behaviour of cold-formed steel channel sections with offset web holes subjected to interior-two-flange loading
}

\author{
Asraf Uzzaman ${ }^{a}$, James B.P. Lim ${ }^{\mathrm{b}, *}$, David Nash ${ }^{\mathrm{a}}$, Jim Rhodes ${ }^{\mathrm{a}}$, Ben Young ${ }^{\mathrm{c}}$ \\ a Department of Mechanical and Aerospace Engineering, The University of Strathclyde, 75 Montrose Street, Glasgow G1 1XJ, UK \\ b SPACE, David Keir Building, Queen's University, Belfast BT9 5AG, UK \\ ${ }^{\mathrm{c}}$ Department of Civil Engineering, The University of Hong Kong, Pokfulam Road, Hong Kong
}

\section{A R T I C L E I N F O}

\section{Article history:}

Received 4 September 2011

Received in revised form

30 September 2011

Accepted 30 September 2011

Available online 30 October 2011

\section{Keywords:}

Cold-formed steel

Web crippling

Finite element analysis

Web hole

Channel section

Reduction factor

Design recommendations

\begin{abstract}
A B S T R A C T
Cold-formed steel sections are often used as wall studs or floor joists; such sections often include web holes for ease of installation of the services. Cold-formed steel design codes, however, do not consider the effect of such web holes. In this paper, a combination of experimental tests and non-linear elastoplastic finite element analyses are used to investigate the effect of such holes on web crippling under interior-two-flange (ITF) loading conditions; the cases of both flange fastened and flange unfastened are considered. A good agreement between the experimental tests and finite element analyses was obtained. The finite element model was then used for the purposes of a parametric study on the effect of different sizes and position of holes in the web. It was demonstrated that the main factors influencing the web crippling strength are the ratio of the hole depth to the depth of the web, and the ratio of the distance from the edge of the bearing to the flat depth of web. Design recommendations in the form of web crippling strength reduction factors are proposed, that are conservative to both the experimental and finite element results.
\end{abstract}

(c) 2011 Elsevier Ltd. All rights reserved.

\section{Introduction}

Cold-formed steel sections are often used as wall studs or floor joists; such sections often include web holes for ease of installation of the electrical or plumbing services. These holes are usually pre-punched in the factory.

Web crushing or crippling at points of concentrated, or localised, load or reaction in thin walled beams is well known to be a significant problem, particularly in the case of beams with slender webs, and is of high importance in the field of cold-formed steel members, as such members are generally not stiffened against this type of loading. At points of concentrated loading and supports, severe lateral loading can result in a local buckling in the web [1]. For sections with holes, such web crippling needs to be taken into account.

There has been little research on the web crippling of coldformed steel sections with web holes. Yu and Davis [2] described 20 tests investigating the web crippling strength of back-to-back channel sections with an interior-one-flange loading condition. The test programme comprised both circular and square holes; the holes were located and centred beneath the bearing plate. Strength reduction factors were proposed. Sivakumaran and Zielonka [3] described 103 tests on single lipped channel sections, but again for the interior-one-flange loading condition and with

\footnotetext{
* Corresponding author.

E-mail address: j.lim@qub.ac.uk (J.B.P. Lim).
}

the circular holes located and centred beneath the bearing plate. Again, strength reduction factors were proposed.

LaBoube et al. [4] described 168 tests on single lipped channel sections, covering both interior-one-flange and end-one-flange loading conditions but with the circular holes positioned offset, next to the bearing plate. Strength reduction factors were again proposed. Similar tests were also described by Langan et al. [5], but with rectangular holes. Lagan et al. demonstrated that the main factors influencing the web crippling strength are the ratio of the hole depth to the depth of the web, and the ratio of the distance from the edge of the bearing to the flat depth of web.

More recently, Zhou and Young [6] conducted 84 tests on aluminium alloy square hollow sections with circular holes located at the centre beneath the bearing plates. The web crippling tests were conducted under loading conditions of endtwo-flange (ETF) and interior-two-flange (ITF). Reduction factor equations were also proposed.

Most design specifications for cold-formed steel structural members provide design rules for cold-formed steel channel sections without web holes; only in the case of the North American specification for cold-formed steel sections [7] are reduction factors for web crippling with holes presented, covering the cases of interior-one-flange (IOF) and end-one-flange loading (EOF), and with the flanges of the sections unfastened to the support. The holes are assumed to be located at the mid-height of the specimen having a longitudinal clear offset distance between the edge of the bearing plates and the web hole. 


\begin{tabular}{|c|c|c|c|}
\hline \multicolumn{2}{|c|}{ Nomenclature } & \multirow{2}{*}{$\begin{array}{l}P_{\text {EXP }} \\
P_{F E A}\end{array}$} & \multirow{2}{*}{$\begin{array}{l}\text { experimental ultimate web crippling load per web } \\
\text { web crippling strength per web predicted from finite } \\
\text { element (FEA) }\end{array}$} \\
\hline$A$ & web holes ratio & & \\
\hline$a$ & diameter of circular web holes & $P_{m}$ & mean value of tested-to-predicted load ratio \\
\hline$b_{f}$ & overall flange width of section & $R$ & reduction factor \\
\hline$b_{l}$ & overall lip width of section & $R_{P}$ & proposed reduction factor \\
\hline $\mathrm{COV}$ & coefficient of variation & $r_{i}$ & inside corner radius of section \\
\hline DL & dead load & $t$ & thickness of section \\
\hline$D$ & overall web depth of section & $V_{F}$ & coefficient of variation of fabrication factor \\
\hline$E$ & Young's modulus of elasticity & $V_{M}$ & coefficient of variation of material factor \\
\hline FEA & finite element analysis & $V_{P}$ & coefficient of variation of tested-to-predicted load \\
\hline$F_{m}$ & mean value of fabrication factor & & ratio \\
\hline $\begin{array}{l}f_{y} \\
h\end{array}$ & $\begin{array}{l}\text { material yield strength } \\
\text { depth of the flat portion of web }\end{array}$ & $x$ & $\begin{array}{l}\text { horizontal clear distance of the web holes to the near } \\
\text { edge of the bearing plate }\end{array}$ \\
\hline$L$ & length of the specimen & $X$ & web holes distance ratio \\
\hline LL & live load & $\beta$ & reliability index \\
\hline$M_{m}$ & mean value of material factor & $\varepsilon_{f}$ & elongation (tensile strain) at fracture \\
\hline$N$ & length of the bearing plate & $\phi$ & resistance factor \\
\hline$P$ & $\begin{array}{l}\text { experimental and finite element ultimate web crip- } \\
\text { pling load per web }\end{array}$ & $\begin{array}{l}\sigma_{0.2} \\
\sigma_{u}\end{array}$ & $\begin{array}{l}\text { static } 0.2 \% \text { proof stress } \\
\text { static ultimate tensile strength }\end{array}$ \\
\hline
\end{tabular}

In this paper, a combination of experimental tests and non-linear elasto-plastic finite element analyses (FEA) are used to investigate the effect of offset circular web holes on the web crippling strength of lipped channel sections for the interior-two-flange (ITF) loading condition, as shown in Fig.1; the cases of both flange fastened and flange unfastened to the support are considered.

The general purpose finite element program ANSYS [8] was used for the numerical investigation. A good agreement between the experimental tests and finite element analyses was obtained. The finite element model was then used for the purposes of a parametric study of the effect of different sizes and position of holes in the web. Design recommendations in the form of web crippling strength reduction factors are proposed, that are conservative to both the experimental and finite element results.

\section{Experiment investigation}

\subsection{Test specimens}

A test programme was conducted on lipped channel sections, as shown in Fig. 2, with circular web holes subjected to web crippling. The size of the web holes was varied in order to investigate the effect of the web holes on the web crippling strength. The circular holes with nominal diameters $(a)$ ranging from 40 to $240 \mathrm{~mm}$ were considered in the experimental investigation. The ratio of the diameter of the holes to the depth of the flat portion of the webs $(a / h)$ was 0.4 . All the test specimens were fabricated with web holes located at the mid-depth of the webs. The horizontal clear distance of the web holes to the near edge of the bearing plate $(x)$ is shown in Fig. 1 .

Channel sections without holes were also tested. The test specimens comprised five different section sizes, having the nominal thicknesses ranging from 1.3 to $2.0 \mathrm{~mm}$; the nominal depth of the webs and the flange widths ranged from 142 to $302 \mathrm{~mm}$. The measured web slenderness $(h / t)$ values of the channel sections ranged from 116 to 176 . The specimen lengths $(L)$ were determined according to the NAS Specification [7]. Generally, the distance from the edge of the bearing plate to the end of the member was set to be 1.5 times the overall depth of the web $(d)$ rather than 1.5 times the depth of the flat portion of the web $(h)$, the latter being the minimum specified in the specifications. Tables 1 and 2 shows the measured test specimen dimensions for the flange unfastened and fastened conditions, respectively, using the nomenclature defined in Figs. 1 and 2 for the ITF loading condition. The bearing plates were fabricated using with high strength steel having a thickness of $25 \mathrm{~mm}$. Two lengths of
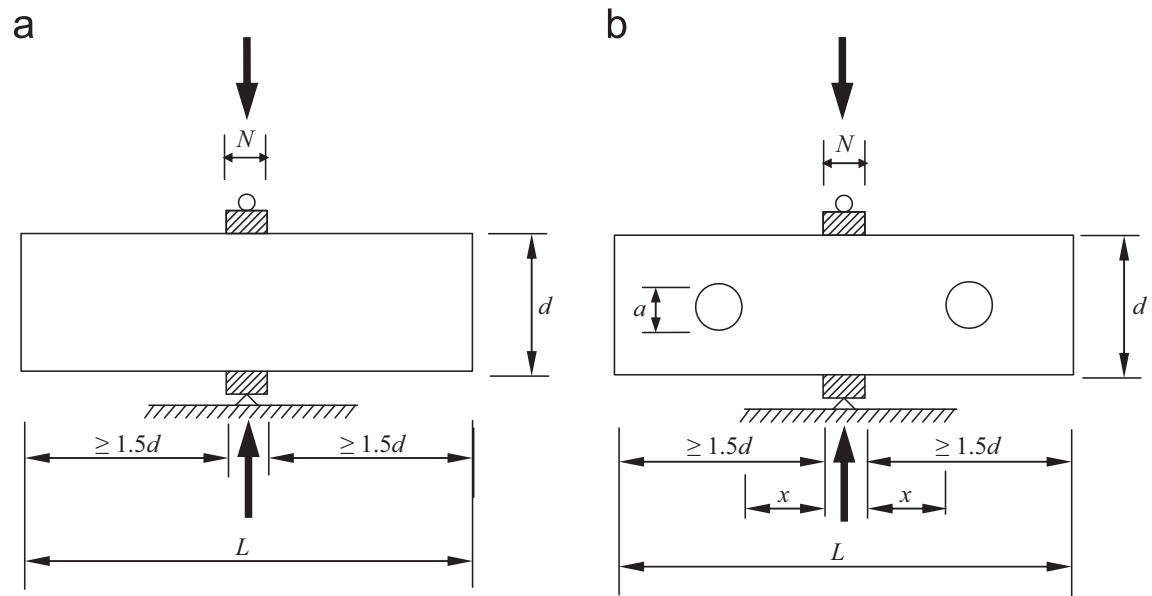

Fig. 1. ITF loading condition: (a) without holes and (b) with holes. 
bearing plates $(N)$ was used: the full flange width of the channel section and the half width of the channel section.

\subsection{Specimens labelling}

In Tables 1 and 2, the specimens were labelled such that the loading condition, the nominal dimension of the specimen and the length of the bearing as well as the ratio of the diameter of the holes to the depth of the flat portion of the webs $(a / h)$ could be identified from the label. For example, the labels " $202 \times 65 \times 13$ t1.4N32.5A0FR" and " $202 \times 65 \times 13-t 1.4 N 32.5 A 0 F X$ define the following specimens:

- The following symbols are the nominal dimensions $\left(d \times b_{f} \times b_{l}\right.$ $-\mathrm{t} 1.4)$ of the specimens in millimetres $(202 \times 65 \times 13-\mathrm{t} 1.4$ means $d=202 \mathrm{~mm} ; b_{f}=65 \mathrm{~mm} ; b_{l}=13 \mathrm{~mm}$ and $t=1.4 \mathrm{~mm}$ ).

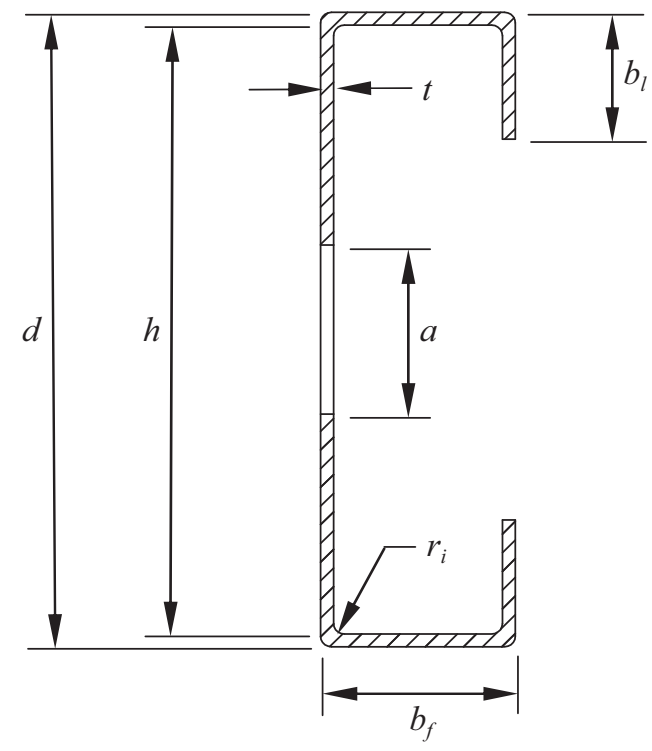

Fig. 2. Definition of symbols.
- The notation "N32.5" indicates the length of bearing in millimetres (32.5 mm).

- The last notations "A0.2", "A0.4", "A0.6" and "A0.8" stand for the ratios of the diameter of the holes to the depth of the flat portion of the webs $(a / h)$ were $0.2,0.4,0.6$ and 0.8 , respectively (A0.2 means $a / h=0.2 ;$ A0.8 means $a / h=0: 8$ ).

- Ten tests were conducted on the channel section specimens without web holes that are denoted by "A0". FR means flanges unfastened to the support and FX means flanges fastened to the support.

\subsection{Material properties}

Tensile coupon tests were carried out to determine the material properties of the channel specimens. The tensile coupons were taken from the centre of the web plate in the longitudinal direction of the untested specimens. The tensile coupons were prepared and tested according to the British Standard for Testing and Materials [9] for the tensile testing of metals using $12.5 \mathrm{~mm}$ wide coupons of a gauge length $50 \mathrm{~mm}$. The coupons were tested in a MTS displacement controlled testing machine using friction grips. Two strain gauges and a calibrated extensometer of $50 \mathrm{~mm}$ gauge length were used to measure the longitudinal strain. The material properties obtained from the tensile coupon tests are summarised in Table 3, which includes the measured static $2 \%$ proof stress $\left(\sigma_{0.2}\right)$, the static tensile strength $\left(\sigma_{u}\right)$ and the elongation after fracture $\left(\varepsilon_{f}\right)$ based on gauge length of $50 \mathrm{~mm}$.

\subsection{Test rig and procedure}

The specimens were tested under the interior-two-flange (ITF) loading condition specified in the NAS Specification [7], as shown in Fig. 3(a). For the ITF loading conditions, two identical bearing plates of the same width were positioned at the end and the midlength of each specimen, respectively. Hinge supports were simulated by two half rounds in the line of action of the force. A servo-controlled Tinius-Olsen testing machine was used to apply a concentrated compressive force to the test specimens. Displacement control was used to drive the hydraulic actuator at a constant speed of $0.05 \mathrm{~mm} / \mathrm{min}$ for all the test specimens.

Table 1

Measured specimen dimensions and experimental ultimate loads for flanges unfastened condition.

\begin{tabular}{|c|c|c|c|c|c|c|c|c|}
\hline Specimen & $\begin{array}{l}\text { Web, } \\
d(\mathrm{~mm})\end{array}$ & $\begin{array}{l}\text { Flange, } \\
b_{f}(\mathrm{~mm})\end{array}$ & $\begin{array}{l}\text { Lip, } \\
b_{l}(\mathrm{~mm})\end{array}$ & $\begin{array}{l}\text { Thickness, } \\
t(\mathrm{~mm})\end{array}$ & $\begin{array}{l}\text { Fillet, } \\
r_{i}(\mathrm{~mm})\end{array}$ & $\begin{array}{l}\text { Holes, } \\
a(\mathrm{~mm})\end{array}$ & $\begin{array}{l}\text { Length, } \\
L(\mathrm{~mm})\end{array}$ & $\begin{array}{l}\text { Exp. load per } \\
\text { web, } P_{E X P}(\mathrm{kN})\end{array}$ \\
\hline $142 \times 60 \times 13-\mathrm{t} 1.3 \mathrm{~N} 30 \mathrm{AOFR}$ & 142.9 & 59.0 & 15.2 & 1.21 & 4.8 & 0.0 & 501.0 & 5.6 \\
\hline $142 \times 60 \times 13-\mathrm{t} 1.3 \mathrm{~N} 30 \mathrm{~A} 0.4 \mathrm{FR}$ & 144.6 & 57.0 & 15.4 & 1.22 & 4.8 & 55.2 & 502.7 & 4.5 \\
\hline $142 \times 60 \times 13-\mathrm{t} 1.3 \mathrm{~N} 60 \mathrm{AOFR}$ & 142.4 & 60.0 & 16.0 & 1.21 & 4.8 & 0.0 & 551.3 & 6.0 \\
\hline $142 \times 60 \times 13-\mathrm{t} 1.3 \mathrm{~N} 60 \mathrm{~A} 0.4 \mathrm{FR}$ & 142.5 & 59.8 & 14.5 & 1.20 & 4.8 & 54.8 & 550.9 & 4.9 \\
\hline $172 \times 65 \times 13-\mathrm{t} 1.3 \mathrm{~N} 32.5 \mathrm{AOFR}$ & 172.7 & 64.8 & 14.9 & 1.23 & 4.8 & 0.0 & 599.9 & 5.7 \\
\hline $172 \times 65 \times 13-\mathrm{t} 1.3 \mathrm{~N} 32.5 \mathrm{~A} 0.4 \mathrm{FR}$ & 172.7 & 64.3 & 14.9 & 1.24 & 4.8 & 67.1 & 606.8 & 4.6 \\
\hline $172 \times 65 \times 13-\mathrm{t} 1.3 \mathrm{~N} 65 \mathrm{AOFR}$ & 172.8 & 64.0 & 14.8 & 1.26 & 4.8 & 0.0 & 649.8 & 6.3 \\
\hline $172 \times 65 \times 13-\mathrm{t} 1.3 \mathrm{~N} 65 \mathrm{~A} 0.4 \mathrm{FR}$ & 173.0 & 64.3 & 14.9 & 1.27 & 4.8 & 67.0 & 650.9 & 5.2 \\
\hline $202 \times 65 \times 13-\mathrm{t} 1.4 \mathrm{~N} 32.5 \mathrm{AOFR}$ & 202.5 & 63.6 & 16.0 & 1.40 & 4.8 & 0.0 & 678.3 & 6.8 \\
\hline $202 \times 65 \times 13-\mathrm{t} 1.4 \mathrm{~N} 32.5 \mathrm{A0} .4 \mathrm{FR}$ & 202.3 & 64.0 & 15.3 & 1.44 & 4.8 & 79.1 & 675.6 & 5.6 \\
\hline $202 \times 65 \times 13-\mathrm{t} 1.4 \mathrm{~N} 65 \mathrm{AOFR}$ & 202.5 & 64.0 & 17.5 & 1.44 & 4.8 & 0.0 & 701.0 & 7.4 \\
\hline $202 \times 65 \times 13-\mathrm{t} 1.4 \mathrm{~N} 65 \mathrm{A0} .4 \mathrm{FR}$ & 202.4 & 63.9 & 17.0 & 1.39 & 4.8 & 79.1 & 701.4 & 5.8 \\
\hline $262 \times 65 \times 13-\mathrm{t} 1.6 \mathrm{~N} 32.5$ AOFR & 262.6 & 64.6 & 15.8 & 1.48 & 5.5 & 0.0 & 850.5 & 6.6 \\
\hline $262 \times 65 \times 13-\mathrm{t} 1.6 \mathrm{~N} 32.5 \mathrm{A0} .4 \mathrm{FR}$ & 263.4 & 63.4 & 14.4 & 1.52 & 5.0 & 102.5 & 836.0 & 5.3 \\
\hline $262 \times 65 \times 13-\mathrm{t} 1.6 \mathrm{~N} 65 \mathrm{AOFR}$ & 263.1 & 65.9 & 15.1 & 1.54 & 5.0 & 0.0 & 907.3 & 7.7 \\
\hline $262 \times 65 \times 13-\mathrm{t} 1.6 \mathrm{~N} 65 \mathrm{~A} 0.4 \mathrm{FR}$ & 262.5 & 63.8 & 14.4 & 1.47 & 5.5 & 102.5 & 896.7 & 5.5 \\
\hline $302 \times 90 \times 18-\mathrm{t} 2 \mathrm{~N} 44 \mathrm{~A} 0.4 \mathrm{FR}$ & 304.0 & 87.9 & 18.0 & 1.93 & 4.8 & 118.2 & 998.9 & 10.2 \\
\hline $302 \times 90 \times 18-\mathrm{t} 2 \mathrm{~N} 90 \mathrm{AOFR}$ & 303.8 & 88.8 & 18.7 & 1.96 & 4.8 & 0.0 & 1052.2 & 14.1 \\
\hline $302 \times 90 \times 18-\mathrm{t} 2 \mathrm{~N} 90 \mathrm{~A} 0.4 \mathrm{FR}$ & 303.1 & 87.8 & 19.1 & 1.94 & 4.8 & 118.0 & 1050.9 & 11.3 \\
\hline
\end{tabular}

Note: $1 \mathrm{kip}=4.45 \mathrm{kN}$. 
Table 2

Measured specimen dimensions and experimental ultimate loads for flanges fastened condition.

\begin{tabular}{|c|c|c|c|c|c|c|c|c|}
\hline Specimen & $\begin{array}{l}\text { Web, } \\
d(\mathrm{~mm})\end{array}$ & $\begin{array}{l}\text { Flange, } \\
b_{f}(\mathrm{~mm})\end{array}$ & $\begin{array}{l}\text { Lip, } \\
b_{l}(\mathrm{~mm})\end{array}$ & $\begin{array}{l}\text { Thickness, } \\
t(\mathrm{~mm})\end{array}$ & $\begin{array}{l}\text { Fillet, } \\
r_{i}(\mathrm{~mm})\end{array}$ & $\begin{array}{l}\text { Holes, } \\
a(\mathrm{~mm})\end{array}$ & $\begin{array}{l}\text { Length, } \\
L(\mathrm{~mm})\end{array}$ & $\begin{array}{l}\text { Exp. load per } \\
\text { web, } P_{E X P}(\mathrm{kN})\end{array}$ \\
\hline $142 \times 60 \times 13-\mathrm{t} 1.3 \mathrm{~N} 30 \mathrm{AOFX}$ & 142.2 & 59.4 & 15.5 & 1.22 & 4.8 & 0.0 & 502.3 & 7.5 \\
\hline $142 \times 60 \times 13-\mathrm{t} 1.3 \mathrm{~N} 30 \mathrm{~A} 0.4 \mathrm{FX}$ & 142.1 & 59.3 & 14.4 & 1.20 & 4.8 & 55.6 & 499.1 & 7.0 \\
\hline $142 \times 60 \times 13-\mathrm{t} 1.3 \mathrm{~N} 60 \mathrm{AOFX}$ & 142.5 & 60.1 & 16.0 & 1.21 & 4.8 & 0.0 & 555.0 & 8.1 \\
\hline $142 \times 60 \times 13-\mathrm{t} 1.3 \mathrm{~N} 60 \mathrm{~A} 0.4 \mathrm{FX}$ & 142.5 & 60.1 & 15.1 & 1.21 & 4.8 & 55.4 & 552.3 & 7.3 \\
\hline $172 \times 65 \times 13-\mathrm{t} 1.3 \mathrm{~N} 32.5 \mathrm{AOFX}$ & 172.8 & 63.6 & 15.1 & 1.26 & 4.8 & 0.0 & 601.1 & 8.9 \\
\hline $172 \times 65 \times 13-\mathrm{t} 1.3 \mathrm{~N} 32.5 \mathrm{~A} 0.4 \mathrm{FX}$ & 172.6 & 64.5 & 15.1 & 1.20 & 4.8 & 67.8 & 603.8 & 7.7 \\
\hline $172 \times 65 \times 13-\mathrm{t} 1.3 \mathrm{~N} 65 \mathrm{AOFX}$ & 172.5 & 64.4 & 14.8 & 1.25 & 4.5 & 0.0 & 649.1 & 9.5 \\
\hline $172 \times 65 \times 13-\mathrm{t} 1.3 \mathrm{~N} 65 \mathrm{~A} 0.4 \mathrm{FX}$ & 173.0 & 64.9 & 14.9 & 1.22 & 4.8 & 67.7 & 649.5 & 8.5 \\
\hline $202 \times 65 \times 13-\mathrm{t} 1.4 \mathrm{~N} 32.5$ AOFX & 202.1 & 64.7 & 15.1 & 1.44 & 4.5 & 0.0 & 677.6 & 11.5 \\
\hline $202 \times 65 \times 13-\mathrm{t} 1.4 \mathrm{~N} 32.5 \mathrm{~A} 0.4 \mathrm{FX}$ & 202.3 & 63.4 & 15.2 & 1.44 & 4.8 & 79.5 & 676.7 & 9.6 \\
\hline $202 \times 65 \times 13-\mathrm{t} 1.4 \mathrm{~N} 65 \mathrm{AOFX}$ & 202.4 & 63.5 & 14.9 & 1.43 & 4.5 & 0.0 & 699.9 & 11.7 \\
\hline $202 \times 65 \times 13-\mathrm{t} 1.4 \mathrm{~N} 65 \mathrm{~A} 0.4 \mathrm{FX}$ & 202.5 & 63.7 & 15.0 & 1.44 & 4.8 & 79.5 & 702.4 & 10.3 \\
\hline $262 \times 65 \times 13-\mathrm{t} 1.6 \mathrm{~N} 32.5 \mathrm{AOFX}$ & 263.1 & 63.5 & 15.0 & 1.51 & 5.0 & 0.0 & 849.0 & 11.5 \\
\hline $262 \times 65 \times 13-\mathrm{t} 1.6 \mathrm{~N} 32.5 \mathrm{~A} 0.4 \mathrm{FX}$ & 263.4 & 62.6 & 15.8 & 1.52 & 5.0 & 103.0 & 850.9 & 9.6 \\
\hline $262 \times 65 \times 13-\mathrm{t} 1.6 \mathrm{~N} 65 \mathrm{~A} 0.4 \mathrm{FX}$ & 262.8 & 65.1 & 13.8 & 1.51 & 5.0 & 103.0 & 899.7 & 10.2 \\
\hline $302 \times 90 \times 18-\mathrm{t} 2 \mathrm{~N} 44 \mathrm{~A} 0.4 \mathrm{FX}$ & 305.0 & 89.0 & 18.0 & 1.98 & 5.0 & 118.3 & 999.6 & 17.9 \\
\hline $302 \times 90 \times 18-\mathrm{t} 2 \mathrm{~N} 90 \mathrm{AOFX}$ & 303.7 & 87.5 & 18.3 & 1.95 & 5.0 & 0.0 & 1050.7 & 22.3 \\
\hline $302 \times 90 \times 18$-t2N90A0.4FX & 303.6 & 88.3 & 18.5 & 1.87 & 5.0 & 118.9 & 1052.9 & 19.4 \\
\hline
\end{tabular}

Note: $1 \mathrm{kip}=4.45 \mathrm{kN}$.

Table 3

Material properties of specimens.

\begin{tabular}{llll}
\hline Section & $\sigma_{0.2}(\mathrm{MPa})$ & $\sigma_{u}(\mathrm{MPa})$ & $\varepsilon_{f}(\%)$ \\
\hline $142 \times 60 \times 13 \times 1.3$ & 455 & 532 & 23 \\
$172 \times 65 \times 16 \times 1.3$ & 534 & 566 & 10 \\
$202 \times 65 \times 13 \times 1.4$ & 513 & 552 & 11 \\
$262 \times 65 \times 13 \times 1.6$ & 525 & 546 & 10 \\
$302 \times 88 \times 18 \times 2.0$ & 483 & 523 & 11 \\
\hline
\end{tabular}

The load or reaction force was applied by means of bearing plates. The bearing plates were fabricated using a high strength steel. All the bearing plates were machined to specified dimensions, and the thickness was $25 \mathrm{~mm}$. The bearing plates were designed to act across the full flange widths of the channel sections. The flanges of the channel section specimens were fastened and unfastened to the bearing plates during testing as shown in Fig. 3(b) and (c). In the flanges fastened test setup, the flanges were bolted to the bearing plate.

\subsection{Test results}

A total of 37 specimens were tested under the interior-twoflange (ITF) loading condition. The experimental ultimate web crippling loads per web $\left(P_{E X P}\right)$ for the flanges unfastened and fastened condition are given in Tables 1 and 2, respectively. The typical failure mode of web crippling of the specimens is shown in Fig. 6. Fig. 7 and Fig. 8 shows a typical example of the loaddefection curve obtained from a specimen both without and with web holes, and the comparisons with the numerical results.

\section{Numerical investigation}

\subsection{General}

The non-linear elasto-plastic general purpose finite element program ANSYS [8] was used to simulate the channel sections with and without holes subjected to web crippling. The bearing plates, the channel section with circular holes and the interfaces between the bearing plates and the channel section have been modelled. In the finite element model, the measured cross-section dimensions and the material properties obtained from the tests were used. The model was based on the centreline dimensions of the cross-sections. Specific modelling issues are described in the following subsection.

\subsection{Geometry and material properties}

One-quarter of the test set-up was modelled using symmetry about both the vertical transverse and horizontal planes is shown in Figs. 4(b) and 5(b). Contact surfaces are defined between the bearing plate and the cold-formed steel section.

The value of Young's modulus was $203 \mathrm{kN} / \mathrm{mm}^{2}$ and Poisson's ratio was 0.3 . The material non-linearity was incorporated in the finite element model by specifying 'true' values of stresses and strains. The plasticity of the material was determined by a mathematical model, known as the incremental plasticity model; the true stress $\left(\sigma_{\text {true }}\right)$ and plastic true strain $\left(\varepsilon_{\text {true }}\right)$ were as per the specified method in the ANSYS manual (2011).

\subsection{Element type and mesh sensitivity}

Figs. 4(b) and 5(b) shows details of a typical finite element mesh of the channel section and the bearing plate. The effect of different element sizes in the cross-section of the channel section was investigated to provide both accurate results and reduced computation time. Depending on the size of the section, the finite element mesh sizes ranged from $3 \times 3 \mathrm{~mm}^{2}$ (length by width) to $5 \times 5 \mathrm{~mm}^{2}$

It is necessary to finely mesh the corners of the section due to the transfer of stress from the flange to the web. Nine elements were used around the inside corner radius that forms the bend between the flange and web. Three elements were used at the rounded corners between the flange and lip of the section. The number of elements was chosen so that the aspect ratio of the elements was as close to one as possible. Where holes were modelled, finer mesh sizes were used around the web holes. Mesh sensitivity analyses were performed to verify the number of elements.

The channel sections were modelled using the 4-noded shell element SHELL181. The bearing plates were modelled using the eight-noded solid element SOLID45. CONTAT173 and TARGET170 


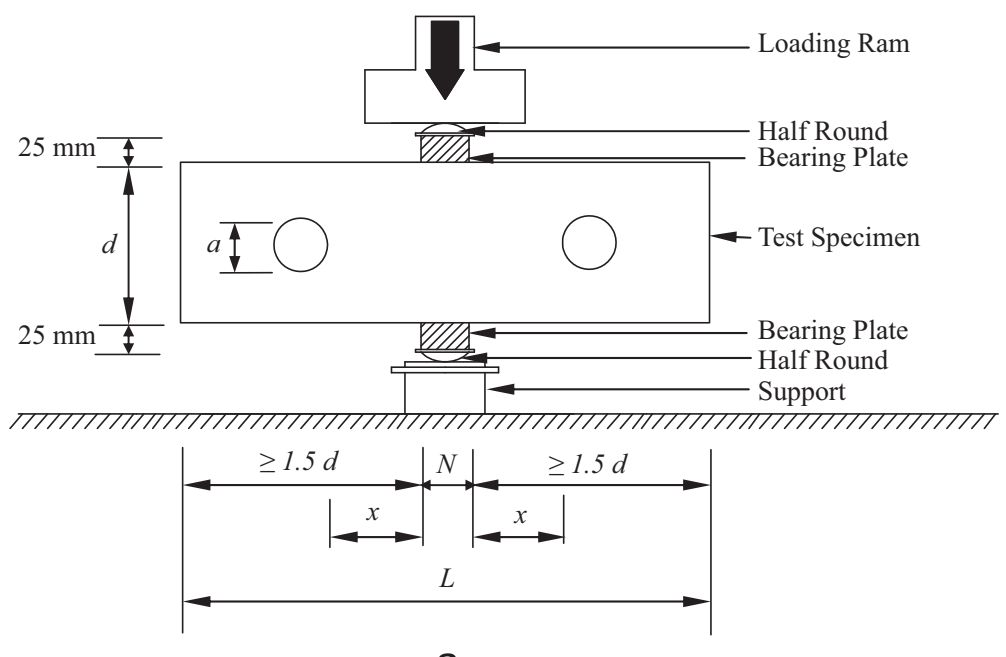

a
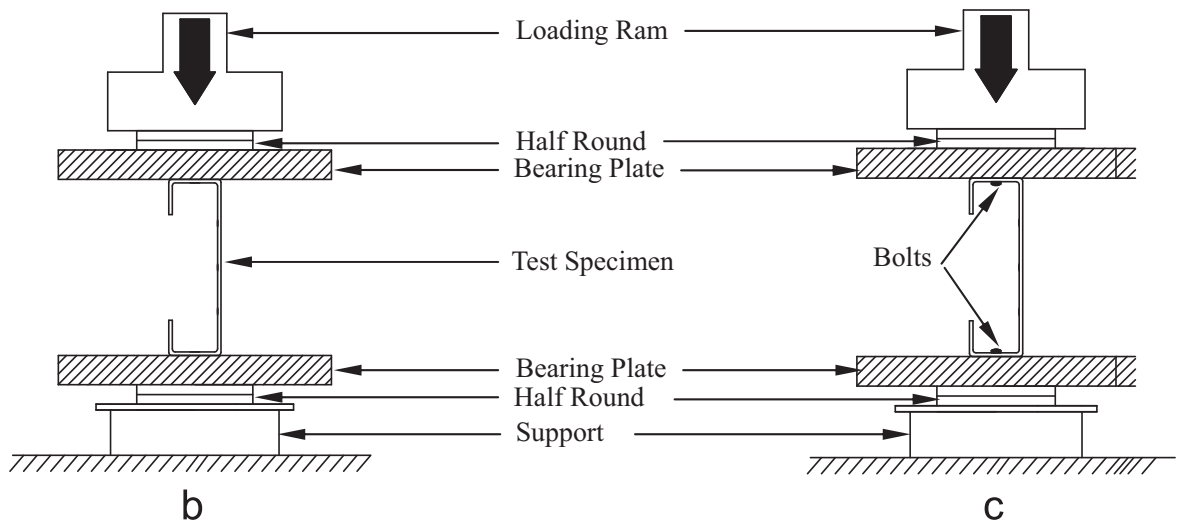

b

C

Fig. 3. Schematic view of test set-up: (a) front view, (b) end view (unfastened flanges) and (c) end view (fastened flanges).

a

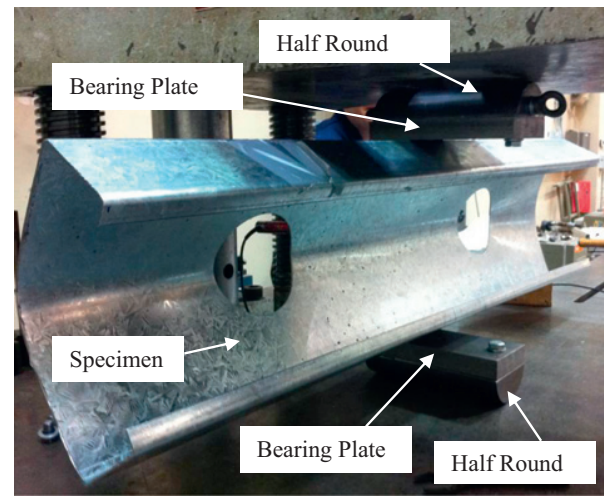

b



Fig. 4. Comparison of experiment and finite element analysis for the flanges unfastened condition: (a) experimental and (b) FEA.

elements were used for modelling contact between the flanges and the load bearing plates.

\subsection{Loading and boundary conditions}

The nodes of the cold-formed section and the bearing plate were restrained to represent the vertical and horizontal symmetry condition. The interface between the bearing plate and the cold-formed steel section were modelled using the surface-to-surface contact option. The bearing plate was the target surface, while the cold-formed steel section was the contact surface. The two contact surfaces were not allowed to penetrate each other.

The vertical load applied to the channel sections in the laboratory tests was modelled using displacement control method; an imposed displacement is applied to the nodes of the top bearing plate where the vertical load is applied. The top bearing plate was restrained against all degrees of freedom, 
a

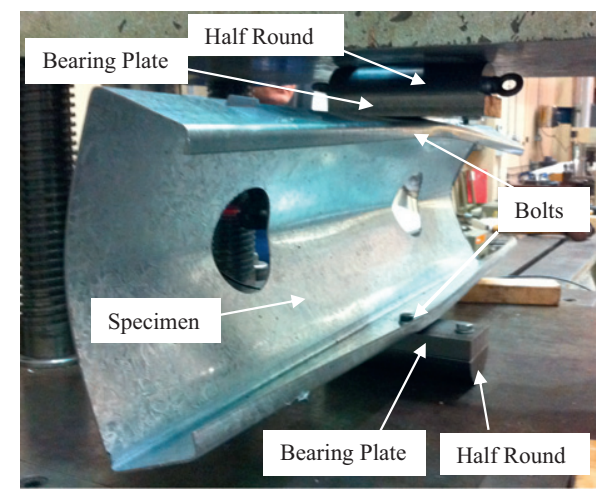

b

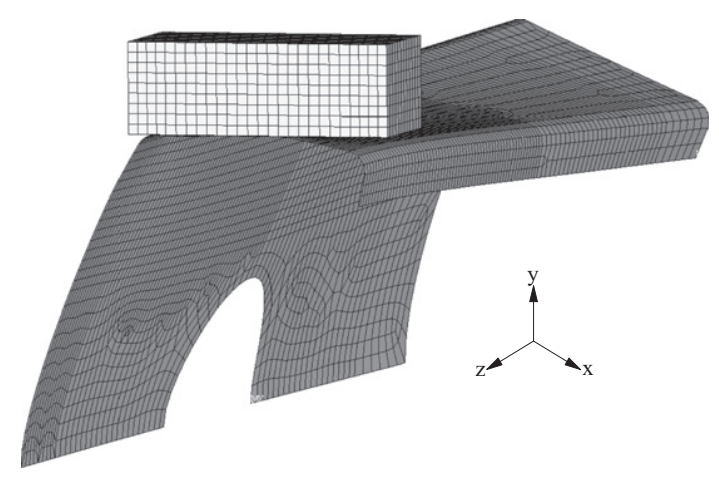

Fig. 5. Comparison of experiment and finite element analysis for the flanges fastened condition: (a) experimental and (b) FEA.

a
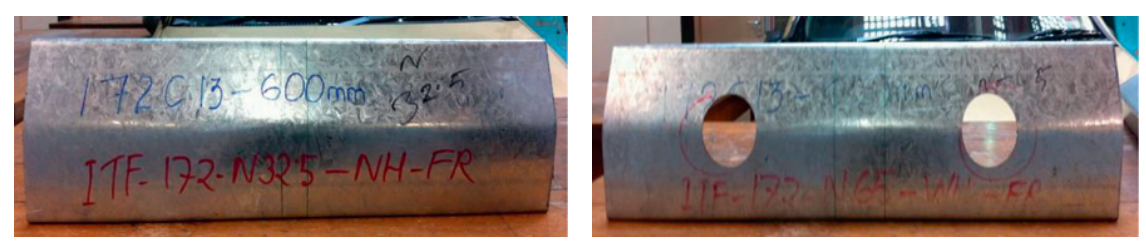

b
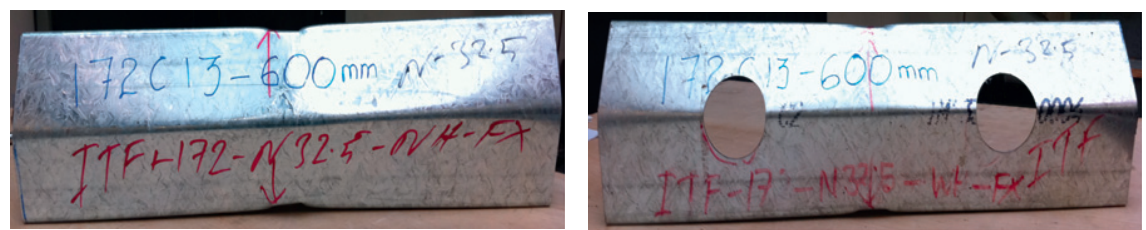

Fig. 6. Typical failure mode of the specimens: (a) specimens for the flanges unfastened condition and (b) specimen for the flanges fastened condition.

Table 4

Comparison of the web crippling strength predicted from the finite element analysis with the experiment results for unfastened condition.

\begin{tabular}{|c|c|c|c|c|c|}
\hline Specimen & $\begin{array}{l}\text { Web slenderness } \\
(h / t)\end{array}$ & Ratio $(a / h)$ & $\begin{array}{l}\text { Exp. load per } \\
\text { web, } P_{E X P}(\mathrm{kN})\end{array}$ & $\begin{array}{l}\text { Web crippling strength } \\
\text { per web predicted from } \\
\text { FEA, } P_{F E A}(\mathrm{kN})\end{array}$ & $\begin{array}{l}\text { Comparison, } \\
P_{E X P} / P_{F E A}\end{array}$ \\
\hline $142 \times 60 \times 13-\mathrm{t} 1.3 \mathrm{~N} 30 \mathrm{AOFR}$ & 116.3 & 0.0 & 5.6 & 5.5 & 1.02 \\
\hline $142 \times 60 \times 13-\mathrm{t} 1.3 \mathrm{~N} 30 \mathrm{~A} 0.4 \mathrm{FR}$ & 116.2 & 0.4 & 4.5 & 4.3 & 1.03 \\
\hline $142 \times 60 \times 13-\mathrm{t} 1.3 \mathrm{~N} 60 \mathrm{A0FR}$ & 115.5 & 0.0 & 6.0 & 5.9 & 1.02 \\
\hline $142 \times 60 \times 13-\mathrm{t} 1.3 \mathrm{~N} 60 \mathrm{A0} .4 \mathrm{FR}$ & 116.5 & 0.4 & 4.9 & 4.7 & 1.06 \\
\hline $172 \times 65 \times 13-\mathrm{t} 1.3 \mathrm{~N} 32.5$ A0FR & 138.4 & 0.0 & 5.7 & 5.6 & 1.02 \\
\hline $172 \times 65 \times 13-\mathrm{t} 1.3 \mathrm{~N} 32.5 \mathrm{~A} 0.4 \mathrm{FR}$ & 137.2 & 0.4 & 4.6 & 4.6 & 0.98 \\
\hline $172 \times 65 \times 13-\mathrm{t} 1.3 \mathrm{~N} 65 \mathrm{AOFR}$ & 135.4 & 0.0 & 6.3 & 6.4 & 0.98 \\
\hline $172 \times 65 \times 13-\mathrm{t} 1.3 \mathrm{~N} 65$ A0.4FR & 134.5 & 0.4 & 5.2 & 5.3 & 0.97 \\
\hline $202 \times 65 \times 13-\mathrm{t} 1.4 \mathrm{~N} 32.5$ AOFR & 143.1 & 0.0 & 6.8 & 6.9 & 0.99 \\
\hline $202 \times 65 \times 13-\mathrm{t} 1.4 \mathrm{~N} 32.5 \mathrm{~A} 0.4 \mathrm{FR}$ & 138.3 & 0.4 & 5.6 & 5.9 & 0.96 \\
\hline $202 \times 65 \times 13-\mathrm{t} 1.4 \mathrm{~N} 65 \mathrm{AOFR}$ & 139.0 & 0.0 & 7.4 & 7.7 & 0.96 \\
\hline $202 \times 65 \times 13-\mathrm{t} 1.4 \mathrm{~N} 65$ A0.4FR & 143.7 & 0.4 & 5.8 & 5.6 & 1.03 \\
\hline $262 \times 65 \times 13-\mathrm{t} 1.6 \mathrm{~N} 32.5$ A0FR & 175.9 & 0.0 & 6.6 & 6.5 & 1.01 \\
\hline $262 \times 65 \times 13-\mathrm{t} 1.6 \mathrm{~N} 32.5 \mathrm{~A} 0.4 \mathrm{FR}$ & 170.8 & 0.4 & 5.3 & 5.5 & 0.96 \\
\hline $262 \times 65 \times 13-\mathrm{t} 1.6 \mathrm{~N} 65$ A0.4FR & 176.9 & 0.4 & 5.5 & 5.4 & 1.02 \\
\hline $302 \times 90 \times 18-\mathrm{t} 2 \mathrm{~N} 44 \mathrm{~A} 0.4 \mathrm{FR}$ & 155.7 & 0.4 & 10.2 & 9.9 & 1.03 \\
\hline $302 \times 90 \times 18-\mathrm{t} 2 \mathrm{~N} 90 \mathrm{AOFR}$ & 153.4 & 0.0 & 14.1 & 13.5 & 1.04 \\
\hline $302 \times 90 \times 18-\mathrm{t} 2 \mathrm{~N} 90 \mathrm{~A} 0.4 \mathrm{FR}$ & 154.5 & 0.4 & 11.3 & 10.7 & 1.06 \\
\hline Mean & & & & & 1.01 \\
\hline $\mathrm{COV}$ & & & & & 0.03 \\
\hline
\end{tabular}

except for the translational degree of freedom in the $Y$ direction. In the flanges fastened condition, the node coupling method was used in the region where the flanges connected to the bearing plates. The nodes were coupled together in all degrees of freedom.

\subsection{Verification of finite element model}

In order to validate the finite element model, the experimental failure loads were compared against the failure load predicted by 
Table 5

Comparison of the web crippling strength predicted from the finite element analysis with the experiment results for fastened condition.

\begin{tabular}{|c|c|c|c|c|c|}
\hline Specimen & $\begin{array}{l}\text { Web } \\
\text { slenderness, } \\
h / t\end{array}$ & Ratio, $a / h$ & $\begin{array}{l}\text { Exp. load per } \\
\text { web, } P_{E X P}\end{array}$ & $\begin{array}{l}\text { Web crippling strength } \\
\text { per web predicted from } \\
\text { FEA, } P_{\text {FEA }}(\mathrm{kN})\end{array}$ & $\begin{array}{l}\text { Comparison, } \\
P_{E X P} / P_{F E A}\end{array}$ \\
\hline $142 \times 60 \times 13-\mathrm{t} 1.3 \mathrm{~N} 30 \mathrm{AOFX}$ & 114.52 & 0.00 & 7.48 & 7.84 & 0.95 \\
\hline $142 \times 60 \times 13-\mathrm{t} 1.3 \mathrm{~N} 30 \mathrm{~A} 0.4 \mathrm{FX}$ & 116.42 & 0.40 & 6.95 & 6.95 & 1.00 \\
\hline $142 \times 60 \times 13-\mathrm{t} 1.3 \mathrm{~N} 60 \mathrm{AOFX}$ & 115.75 & 0.00 & 8.14 & 8.23 & 0.99 \\
\hline $142 \times 60 \times 13-\mathrm{t} 1.3 \mathrm{~N} 60 \mathrm{A0} 0.4 \mathrm{FX}$ & 115.80 & 0.40 & 7.29 & 7.63 & 0.96 \\
\hline $172 \times 65 \times 13-\mathrm{t} 1.3 \mathrm{~N} 32.5 \mathrm{AOFX}$ & 135.16 & 0.00 & 8.92 & 8.99 & 0.99 \\
\hline $172 \times 65 \times 13-\mathrm{t} 1.3 \mathrm{~N} 32.5 \mathrm{A0} .4 \mathrm{FX}$ & 141.83 & 0.40 & 7.68 & 7.51 & 1.02 \\
\hline $172 \times 65 \times 13-\mathrm{t} 1.3 \mathrm{~N} 65 \mathrm{~A} 0 \mathrm{FX}$ & 135.98 & 0.00 & 9.48 & 9.58 & 0.99 \\
\hline $172 \times 65 \times 13-\mathrm{t} 1.3 \mathrm{~N} 65 \mathrm{~A} 0.4 \mathrm{FX}$ & 139.82 & 0.40 & 8.46 & 8.30 & 1.02 \\
\hline $202 \times 65 \times 13-\mathrm{t} 1.4 \mathrm{~N} 32.5 \mathrm{AOFX}$ & 138.33 & 0.00 & 11.46 & 11.07 & 1.04 \\
\hline $202 \times 65 \times 13-\mathrm{t} 1.4 \mathrm{~N} 32.5 \mathrm{~A} 0.4 \mathrm{FX}$ & 138.51 & 0.40 & 9.59 & 10.06 & 0.95 \\
\hline $202 \times 65 \times 13-\mathrm{t} 1.4 \mathrm{~N} 65 \mathrm{A0FX}$ & 139.51 & 0.00 & 11.65 & 11.94 & 0.98 \\
\hline $202 \times 65 \times 13-\mathrm{t} 1.4 \mathrm{~N} 65 \mathrm{~A} 0.4 \mathrm{FX}$ & 138.61 & 0.40 & 10.25 & 10.71 & 0.96 \\
\hline $262 \times 65 \times 13-\mathrm{t} 1.6 \mathrm{~N} 32.5 \mathrm{AOFX}$ & 172.26 & 0.00 & 11.46 & 11.17 & 1.03 \\
\hline $262 \times 65 \times 13-\mathrm{t} 1.6 \mathrm{~N} 32.5 \mathrm{~A} 0.4 \mathrm{FX}$ & 171.28 & 0.40 & 9.64 & 9.65 & 1.00 \\
\hline $262 \times 65 \times 13-\mathrm{t} 1.6 \mathrm{~N} 65 \mathrm{A0} .4 \mathrm{FX}$ & 172.01 & 0.40 & 10.16 & 10.17 & 1.00 \\
\hline $302 \times 90 \times 18-\mathrm{t} 2 \mathrm{~N} 44 \mathrm{~A} 0.4 \mathrm{FX}$ & 152.04 & 0.39 & 17.92 & 17.84 & 1.00 \\
\hline $302 \times 90 \times 18-\mathrm{t} 2 \mathrm{~N} 90 \mathrm{AOFX}$ & 153.75 & 0.00 & 22.31 & 21.72 & 1.03 \\
\hline $302 \times 90 \times 18-\mathrm{t} 2 \mathrm{~N} 90 \mathrm{~A} 0.4 \mathrm{FX}$ & 160.35 & 0.40 & 19.35 & 17.10 & 1.13 \\
\hline Mean & & & & & 1.00 \\
\hline $\mathrm{COV}$ & & & & & 0.04 \\
\hline
\end{tabular}

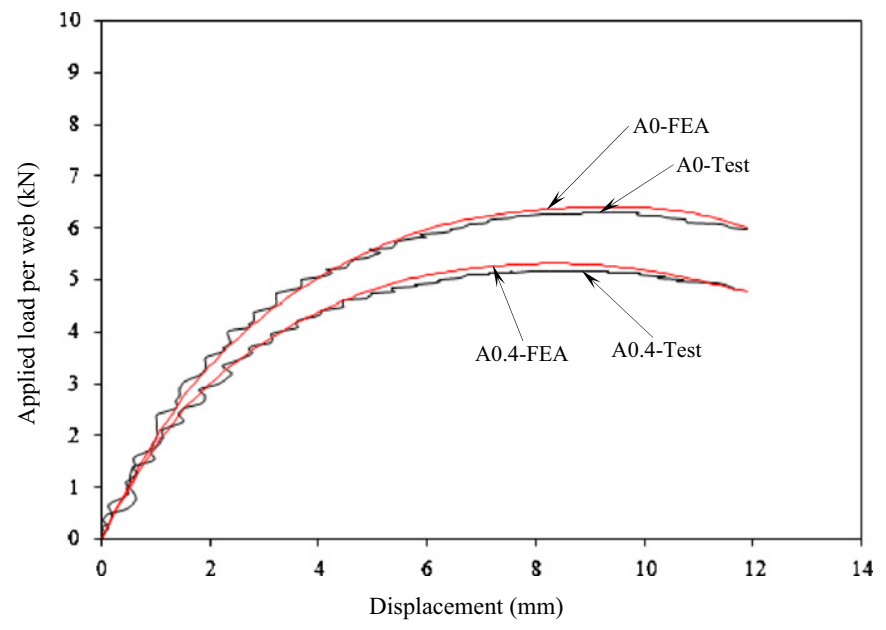

Fig. 7. Comparison web deformation curves for specimen $172 \times 65 \times 13-\mathrm{t} 13$ N65FR.

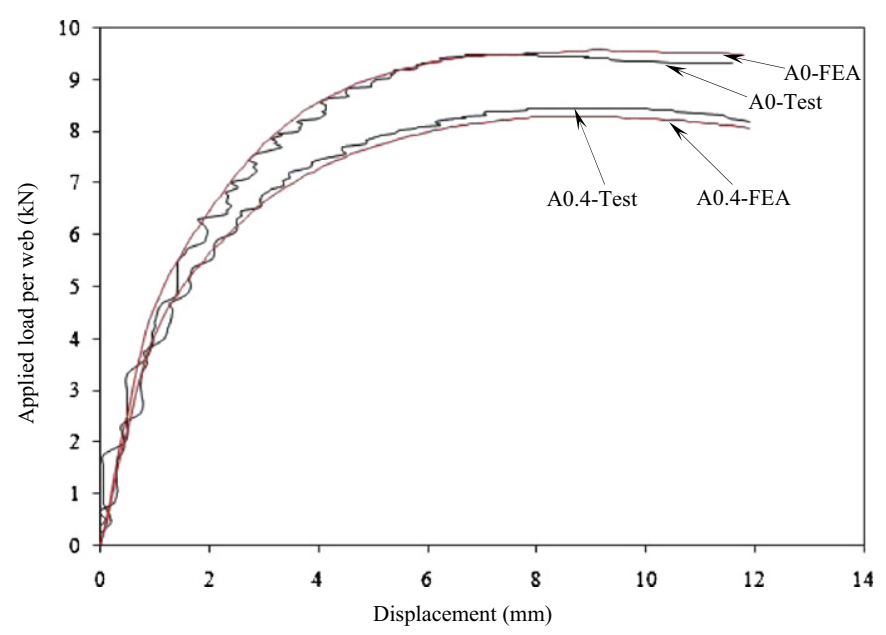

Fig. 8. Comparison web deformation curves for specimen $172 \times 65 \times 13-\mathrm{t} 13$ N65FX. the finite element analysis (Fig. 6). The main objective of this comparison was to verify and check the accuracy of the finite element model. A comparison of the test results $\left(P_{E X P}\right)$ with the numerical results $\left(P_{F E A}\right)$ of web crippling strengths per web is shown in Tables 4 and 5. Load-deflection curves comparing the experimental results and the finite element results are shown in Figs. 7 and 8 covering the cases of both with and without the web holes. It can be seen that good agreement has been achieved between both results for all specimens. The mean value of the $P_{E X P} / P_{F E A}$ ratio is 1.01 and 1.00 with the corresponding coefficient of variation (COV) of 0.03 and 0.04 for the flanges unfastened and fastened condition, respectively. A maximum difference of $6 \%$ and $13 \%$ was observed between the experimental and the numerical results for the specimen $142 \times 60 \times 13-\mathrm{t} 1.3 \mathrm{~N} 60 \mathrm{A0} .4 \mathrm{FR}$ and $302 \times 90 \times 18-\mathrm{t} 2 \mathrm{~N} 90 \mathrm{A0} 0.4 \mathrm{FX}$, respectively. The web crippling failure mode observed from the tests has been also verified by the finite element model for the ITF loading conditions, as shown in Figs. 4 and 5, respectively. It is shown that good agreement is achieved between the experimental and finite element results for both the web crippling strength and the failure mode.

\section{Parametric study}

The finite element model developed closely predicts the behaviour of the channel sections with circular web holes subjected to web crippling. Using this model, parametric studies were carried out to study the effects of web holes and crosssection sizes on the web crippling strengths of channel sections subjected to web crippling.

The web crippling strength predicted was influenced primarily by the ratio of the hole depth to the flat portion of the web, $a / h$, and the location of the hole as defined by the distance of the hole from the edge of the bearing divided by the flat portion of the web, $x / h$. In order to find the effect of $a / h$ and $x / h$ on web crippling strength considering web holes, two separate parametric studies were carried out considering the web holes, the cross-section sizes and location of the holes.

The specimens consisted of two different section sizes, having the thicknesses $(t)$ ranging from 1.4 to $6.0 \mathrm{~mm}$ and the web 
Table 6

Dimensions and web crippling strengths predicted from finite element analysis of parametric study of $a / h$.

\begin{tabular}{|c|c|c|c|c|c|c|c|c|c|c|}
\hline \multirow{2}{*}{ Specimen } & \multirow{2}{*}{$\begin{array}{l}\text { Web, } \\
d(\mathrm{~mm})\end{array}$} & \multirow{2}{*}{$\begin{array}{l}\text { Flange, } \\
b_{f}(\mathrm{~mm})\end{array}$} & \multirow{2}{*}{$\begin{array}{l}\text { Lip, } \\
b_{l}(\mathrm{~mm})\end{array}$} & \multirow{2}{*}{$\begin{array}{l}\text { Thickness, } \\
t(\mathrm{~mm})\end{array}$} & \multirow{2}{*}{$\begin{array}{l}\text { Length, } \\
L(\mathrm{~mm})\end{array}$} & \multicolumn{5}{|c|}{ FEA load per web, $P_{F E A}(\mathrm{kN})$} \\
\hline & & & & & & $\mathrm{A} 0$ & A 0.2 & A0.4 & A0.6 & A0.8 \\
\hline $202 \times 65 \times 13-\mathrm{t} 1.4 \mathrm{~N} 32.5 \mathrm{FR}$ & 202.5 & 63.6 & 16.0 & 1.40 & 678.3 & 6.9 & 6.3 & 5.4 & 4.5 & 3.6 \\
\hline $202 \times 65 \times 13-\mathrm{t} 2.0 \mathrm{~N} 32.5 \mathrm{FR}$ & 202.5 & 63.6 & 16.0 & 2.00 & 678.3 & 17.8 & 15.9 & 13.5 & 11.1 & 8.4 \\
\hline $202 \times 65 \times 13-\mathrm{t} 2.5 \mathrm{~N} 32.5 \mathrm{FR}$ & 202.5 & 63.6 & 16.0 & 2.50 & 678.3 & 30.6 & 27.3 & 22.8 & 18.4 & 14.1 \\
\hline $202 \times 65 \times 13-\mathrm{t} 3.0 \mathrm{~N} 32.5 \mathrm{FR}$ & 202.5 & 63.6 & 16.0 & 3.00 & 678.3 & 43.8 & 41.4 & 34.1 & 27.5 & 21.2 \\
\hline $202 \times 65 \times 13-\mathrm{t} 4.0 \mathrm{~N} 32.5 \mathrm{FR}$ & 202.5 & 63.6 & 16.0 & 4.00 & 678.3 & 86.6 & 74.2 & 61.9 & 49.7 & 38.6 \\
\hline $202 \times 65 \times 13-\mathrm{t} 5.0 \mathrm{~N} 32.5 \mathrm{FR}$ & 202.5 & 63.6 & 16.0 & 5.00 & 678.3 & 129.1 & 112.7 & 96.4 & 76.5 & 59.3 \\
\hline $202 \times 65 \times 13-\mathrm{t} 6.0 \mathrm{~N} 32.5 \mathrm{FR}$ & 202.5 & 63.6 & 16.0 & 6.00 & 678.3 & 185.5 & 161.5 & 137.5 & 107.7 & 83.7 \\
\hline $202 \times 65 \times 13-\mathrm{t} 1.4$ N65FR & 202.5 & 64.0 & 17.5 & 1.44 & 701.0 & 7.6 & 7.0 & 6.1 & 5.1 & 4.0 \\
\hline $202 \times 65 \times 13-\mathrm{t} 2.0 \mathrm{~N} 65 \mathrm{FR}$ & 202.5 & 64.0 & 17.5 & 2.00 & 701.0 & 17.8 & 16.2 & 13.9 & 11.5 & 8.9 \\
\hline $202 \times 65 \times 13-\mathrm{t} 2.5 \mathrm{~N} 65 \mathrm{FR}$ & 202.5 & 64.0 & 17.5 & 2.50 & 701.0 & 30.0 & 27.2 & 23.4 & 19.2 & 14.9 \\
\hline $202 \times 65 \times 13-\mathrm{t} 3.0 \mathrm{~N} 65 \mathrm{FR}$ & 202.5 & 64.0 & 17.5 & 3.00 & 701.0 & 44.6 & 40.3 & 34.5 & 28.4 & 22.3 \\
\hline $202 \times 65 \times 13-\mathrm{t} 4.0 \mathrm{~N} 65 \mathrm{FR}$ & 202.5 & 64.0 & 17.5 & 4.00 & 701.0 & 80.4 & 72.4 & 62.1 & 51.7 & 41.0 \\
\hline $202 \times 65 \times 13-\mathrm{t} 5.0 \mathrm{~N} 65 \mathrm{FR}$ & 202.5 & 64.0 & 17.5 & 5.00 & 701.0 & 124.8 & 111.8 & 95.7 & 79.7 & 63.8 \\
\hline $202 \times 65 \times 13-\mathrm{t} 6.0 \mathrm{~N} 65 \mathrm{FR}$ & 202.5 & 64.0 & 17.5 & 6.00 & 701.0 & 176.2 & 158.6 & 135.0 & 112.8 & 89.8 \\
\hline $302 \times 90 \times 18-\mathrm{t} 2 \mathrm{~N} 44 \mathrm{FR}$ & 304.0 & 87.9 & 18.0 & 1.93 & 998.9 & 12.4 & 11.4 & 9.8 & 8.2 & 6.4 \\
\hline $302 \times 90 \times 18-\mathrm{t} 2.5 \mathrm{~N} 44 \mathrm{FR}$ & 304.0 & 87.9 & 18.0 & 2.50 & 998.9 & 24.9 & 22.7 & 19.5 & 16.0 & 12.1 \\
\hline $302 \times 90 \times 18-\mathrm{t} 3.0 \mathrm{~N} 44 \mathrm{FR}$ & 304.0 & 87.9 & 18.0 & 3.00 & 998.9 & 39.9 & 36.0 & 30.5 & 24.7 & 18.6 \\
\hline $302 \times 90 \times 18-\mathrm{t} 4.0 \mathrm{~N} 44 \mathrm{FR}$ & 304.0 & 87.9 & 18.0 & 4.00 & 998.9 & 74.5 & 70.4 & 59.1 & 47.5 & 36.2 \\
\hline $302 \times 90 \times 18-\mathrm{t} 5.0 \mathrm{~N} 44 \mathrm{FR}$ & 304.0 & 87.9 & 18.0 & 5.00 & 998.9 & 115.1 & 112.9 & 94.8 & 76.2 & 58.7 \\
\hline $302 \times 90 \times 18-\mathrm{t} 6.0 \mathrm{~N} 44 \mathrm{FR}$ & 304.0 & 87.9 & 18.0 & 6.00 & 998.9 & 160.1 & 158.5 & 137.4 & 109.8 & 84.8 \\
\hline $302 \times 90 \times 18-\mathrm{t} 2 \mathrm{~N} 90 \mathrm{FR}$ & 303.8 & 88.8 & 18.7 & 1.96 & 1052.2 & 13.6 & 12.5 & 10.9 & 9.1 & 7.2 \\
\hline $302 \times 90 \times 18-\mathrm{t} 2.5 \mathrm{~N} 90 \mathrm{FR}$ & 303.8 & 88.8 & 18.7 & 2.50 & 1052.2 & 25.9 & 23.8 & 20.6 & 17.0 & 13.1 \\
\hline $302 \times 90 \times 18-\mathrm{t} 3.0 \mathrm{~N} 90 \mathrm{FR}$ & 303.8 & 88.8 & 18.7 & 3.00 & 1052.2 & 40.8 & 37.3 & 32.2 & 26.4 & 20.3 \\
\hline $302 \times 90 \times 18-\mathrm{t} 4.0 \mathrm{~N} 90 \mathrm{FR}$ & 303.8 & 88.8 & 18.7 & 4.00 & 1052.2 & 78.5 & 71.4 & 61.5 & 50.6 & 39.4 \\
\hline $302 \times 90 \times 18-\mathrm{t} 5.0 \mathrm{~N} 90 \mathrm{FR}$ & 303.8 & 88.8 & 18.7 & 5.00 & 1052.2 & 125.0 & 113.7 & 97.8 & 81.2 & 64.2 \\
\hline $302 \times 90 \times 18$-t6.0N90FR & 303.8 & 88.8 & 18.7 & 6.00 & 1052.2 & 180.0 & 163.3 & 140.6 & 117.3 & 93.3 \\
\hline $202 \times 65 \times 13-\mathrm{t} 1.4 \mathrm{~N} 32.5 \mathrm{FX}$ & 202.5 & 63.6 & 16.0 & 1.40 & 678.3 & 10.5 & 10.2 & 9.5 & 8.4 & 7.0 \\
\hline $202 \times 65 \times 13-\mathrm{t} 2.0 \mathrm{~N} 32.5 \mathrm{FX}$ & 202.5 & 63.6 & 16.0 & 2.00 & 678.3 & 21.3 & 20.7 & 19.7 & 18.1 & 15.6 \\
\hline $202 \times 65 \times 13-\mathrm{t} 4.0 \mathrm{~N} 32.5 \mathrm{FX}$ & 202.5 & 63.6 & 16.0 & 4.00 & 678.3 & 77.2 & 75.8 & 73.3 & 68.4 & 60.2 \\
\hline $202 \times 65 \times 13-\mathrm{t} 6.0 \mathrm{~N} 32.5 \mathrm{FX}$ & 202.5 & 63.6 & 16.0 & 6.00 & 678.3 & 159.2 & 155.6 & 151.4 & 141.5 & 125.7 \\
\hline $202 \times 65 \times 13-\mathrm{t} 1.4 \mathrm{~N} 65 \mathrm{FX}$ & 202.5 & 64.0 & 17.5 & 1.44 & 701.0 & 11.9 & 11.6 & 10.7 & 9.5 & 7.9 \\
\hline $202 \times 65 \times 13-\mathrm{t} 2.0 \mathrm{~N} 65 \mathrm{FX}$ & 202.5 & 64.0 & 17.5 & 2.00 & 701.0 & 23.5 & 22.7 & 21.7 & 19.7 & 16.8 \\
\hline $202 \times 65 \times 13-\mathrm{t} 4.0 \mathrm{~N} 65 \mathrm{FX}$ & 202.5 & 64.0 & 17.5 & 4.00 & 701.0 & 86.4 & 85.5 & 83.9 & 79.5 & 69.3 \\
\hline $202 \times 65 \times 13-\mathrm{t} 6.0 \mathrm{~N} 65 \mathrm{FX}$ & 202.5 & 64.0 & 17.5 & 6.00 & 701.0 & 185.7 & 184.5 & 179.3 & 162.7 & 140.4 \\
\hline $302 \times 90 \times 18-\mathrm{t} 2 \mathrm{~N} 44 \mathrm{FX}$ & 304.0 & 87.9 & 18.0 & 1.93 & 998.9 & 18.6 & 18.2 & 16.9 & 15.2 & 12.8 \\
\hline $302 \times 90 \times 18-\mathrm{t} 4.0 \mathrm{~N} 44 \mathrm{FX}$ & 304.0 & 87.9 & 18.0 & 4.00 & 998.9 & 75.9 & 75.6 & 74.5 & 70.6 & 62.9 \\
\hline $302 \times 90 \times 18-\mathrm{t} 6.0 \mathrm{~N} 44 \mathrm{FX}$ & 304.0 & 87.9 & 18.0 & 6.00 & 998.9 & 162.0 & 161.7 & 158.8 & 150.9 & 130.6 \\
\hline $302 \times 90 \times 18-\mathrm{t} 2 \mathrm{~N} 90 \mathrm{FX}$ & 303.9 & 88.8 & 18.7 & 1.96 & 1052.2 & 22.2 & 21.1 & 19.2 & 17.0 & 14.3 \\
\hline $302 \times 90 \times 18-\mathrm{t} 4.0 \mathrm{~N} 90 \mathrm{FX}$ & 303.9 & 88.8 & 18.7 & 4.00 & 1052.2 & 90.5 & 90.1 & 88.9 & 82.2 & 70.7 \\
\hline $302 \times 90 \times 18-\mathrm{t} 6.0 \mathrm{~N} 90 \mathrm{FX}$ & 303.9 & 88.8 & 18.7 & 6.00 & 1052.2 & 193.6 & 192.9 & 190.1 & 178.0 & 154.6 \\
\hline
\end{tabular}

slenderness $(h / t)$ value ranging from 31.8 to 176.9 . The ratios of the diameter of the holes $(a)$ to the depth of the flat portion of the webs $(h)$ were $0.2,0.4,0.6$ and 0.8 . The ratio of the distance of the web holes $(x)$ to the depth of the flat portion of the webs $(h)$ were $0.2,0.4$ and 0.6 .

A total of 200 specimens was analysed in the parametric study investigating the effect of the ratio $a / h$. The cross-section dimensions as well as the web crippling strengths $\left(P_{F E A}\right)$ per web predicted from the FEA are summarised in Table 6 .

A total of 160 specimens was analysed in the parametric study investigating the effect of $x / h$. The cross-section dimensions as well as the web crippling strengths $\left(P_{F E A}\right)$ per web predicted from the FEA are summarised in Table 7.

The effect of $a / h$ and $x / h$ ratio on the web crippling strength on the reduction factor is shown in Figs. 9 and 10 for the C202 Specimen. It is seen from these graphs that the parameter $a / h$ and $x / h$ noticeably affects the web crippling strength and the reduction factor.

\section{Reliability analysis}

The reliability of the cold-formed steel section design rules is evaluated using reliability analysis. The reliability index $(\beta)$ is a relative measure of the safety of the design. A target reliability index of 2.5 for cold-formed steel structural members is recommended as a lower limit in the NAS Specification [7]. The design rules are considered to be reliable if the reliability index is greater than or equal to 2.5. The load combination of $1.2 \mathrm{DL}+1.6 \mathrm{LL}$ as specified in the American Society of Civil Engineers Standard [10] was used in the reliability analysis, where DL is the dead load and LL is the live load. The statistical parameters are obtained from Table F1 of the NAS Specification [7] for compression members, where $M_{m}=1.10, F_{m}=1.00, V_{M}=0.10$, and $V_{F}=0.05$, which are the mean values and coefficients of variation for material properties and fabrication factors.

The statistical parameters $P_{m}$ and $V_{P}$ are the mean value and coefficient of variation of load ratio are shown in Tables 8 and 9 , respectively. In calculating the reliability index, the correction factor in the NAS Specification was used. Reliability analysis is detailed in the NAS Specification [7]. In the reliability analysis, a constant resistance factor $(\phi)$ of 0.85 was used. It is shown that the reliability index $(\beta)$ is greater than the target value of 2.5 as shown in Tables 8 and 9.

\section{Proposed strength reduction factors}

Comparing the failure loads of the channel sections having web holes with the sections without web holes, as shown in 
Table 7

Dimensions and web crippling strengths predicted from finite element analysis of parametric study of $x / h$.

\begin{tabular}{|c|c|c|c|c|c|c|c|c|c|}
\hline \multirow[t]{2}{*}{ Specimen } & \multirow{2}{*}{$\begin{array}{l}\text { Web, } \\
d(\mathrm{~mm})\end{array}$} & \multirow{2}{*}{$\begin{array}{l}\text { Flange, } \\
b_{f}(\mathrm{~mm})\end{array}$} & \multirow{2}{*}{$\begin{array}{l}\text { Lip, } \\
b_{l}(\mathrm{~mm})\end{array}$} & \multirow{2}{*}{$\begin{array}{l}\text { Thickness, } \\
t(\mathrm{~mm})\end{array}$} & \multirow{2}{*}{$\begin{array}{l}\text { Length, } \\
L \text { (mm) }\end{array}$} & \multicolumn{4}{|c|}{ FEA load per web, $P_{F E A}(\mathrm{kN})$} \\
\hline & & & & & & X0 & $\mathrm{X} 0.2$ & $\mathrm{X} 0.4$ & X0.6 \\
\hline $202 \times 65 \times 13-\mathrm{t} 1.4 \mathrm{~N} 32.5$ A0FR & 202.5 & 63.6 & 16.0 & 1.40 & 678.3 & 6.9 & 6.9 & 6.9 & 6.9 \\
\hline $202 \times 65 \times 13-\mathrm{t} 1.4 \mathrm{~N} 32.5 \mathrm{~A} 0.2 \mathrm{FR}$ & 202.5 & 63.6 & 16.0 & 1.40 & 678.3 & 6.3 & 6.3 & 6.3 & 6.3 \\
\hline $202 \times 65 \times 13-\mathrm{t} 1.4 \mathrm{~N} 32.5 \mathrm{~A} 0.4 \mathrm{FR}$ & 202.5 & 63.6 & 16.0 & 1.40 & 678.3 & 5.3 & 5.4 & 5.4 & 5.5 \\
\hline $202 \times 65 \times 13-\mathrm{t} 1.4 \mathrm{~N} 32.5 \mathrm{~A} 0.6 \mathrm{FR}$ & 202.5 & 63.6 & 16.0 & 1.40 & 678.3 & 4.3 & 4.4 & 4.5 & 4.6 \\
\hline $202 \times 65 \times 13-\mathrm{t} 1.4 \mathrm{~N} 32.5 \mathrm{A0} .8 \mathrm{FR}$ & 202.5 & 63.6 & 16.0 & 1.40 & 678.3 & 3.1 & 3.3 & 3.6 & 3.7 \\
\hline $202 \times 65 \times 13-\mathrm{t} 1.4 \mathrm{~N} 65$ A0FR & 202.5 & 64.0 & 17.5 & 1.44 & 701.0 & 7.6 & 7.6 & 7.6 & 7.6 \\
\hline $202 \times 65 \times 13-\mathrm{t} 1.4 \mathrm{~N} 65 \mathrm{~A} 0.2 \mathrm{FR}$ & 202.5 & 64.0 & 17.5 & 1.44 & 701.0 & 7.0 & 7.0 & 7.0 & 7.0 \\
\hline $202 \times 65 \times 13-\mathrm{t} 1.4 \mathrm{~N} 65 \mathrm{~A} 0.4 \mathrm{FR}$ & 202.5 & 64.0 & 17.5 & 1.44 & 702.0 & 5.9 & 6.0 & 6.1 & 6.1 \\
\hline $202 \times 65 \times 13-\mathrm{t} 1.4 \mathrm{~N} 65 \mathrm{~A} 0.6 \mathrm{FR}$ & 202.5 & 64.0 & 17.5 & 1.44 & 703.0 & 4.8 & 5.0 & 5.1 & 5.2 \\
\hline $202 \times 65 \times 13-\mathrm{t} 1.4 \mathrm{~N} 65 \mathrm{~A} 0.8 \mathrm{FR}$ & 202.5 & 64.0 & 17.5 & 1.44 & 704.0 & 3.5 & 3.8 & 4.1 & 4.3 \\
\hline $302 \times 90 \times 18-\mathrm{t} 2 \mathrm{~N} 44 \mathrm{AOFR}$ & 304.0 & 87.9 & 18.0 & 1.93 & 997.9 & 12.4 & 12.4 & 12.4 & 12.4 \\
\hline $302 \times 90 \times 18-\mathrm{t} 2 \mathrm{~N} 44 \mathrm{~A} 0.2 \mathrm{FR}$ & 304.0 & 87.9 & 18.0 & 1.93 & 998.9 & 11.4 & 11.4 & 11.4 & 11.4 \\
\hline $302 \times 90 \times 18-\mathrm{t} 2 \mathrm{~N} 44 \mathrm{~A} 0.4 \mathrm{FR}$ & 304.0 & 87.9 & 18.0 & 1.93 & 999.9 & 9.6 & 9.7 & 9.8 & 9.8 \\
\hline $302 \times 90 \times 18-\mathrm{t} 2 \mathrm{~N} 44 \mathrm{~A} 0.6 \mathrm{FR}$ & 304.0 & 87.9 & 18.0 & 1.93 & 1000.9 & 7.7 & 7.9 & 8.1 & 8.3 \\
\hline $302 \times 90 \times 18-\mathrm{t} 2 \mathrm{~N} 44 \mathrm{~A} 0.8 \mathrm{FR}$ & 304.0 & 87.9 & 18.0 & 1.93 & 1001.9 & 5.5 & 5.9 & 6.4 & 6.7 \\
\hline $302 \times 90 \times 18-\mathrm{t} 2 \mathrm{~N} 90 \mathrm{AOFR}$ & 303.8 & 88.8 & 18.7 & 1.96 & 1051.2 & 13.6 & 13.6 & 13.6 & 13.6 \\
\hline $302 \times 90 \times 18$-t2N90A0.2FR & 303.8 & 88.8 & 18.7 & 1.96 & 1052.2 & 12.5 & 12.5 & 12.5 & 12.5 \\
\hline $302 \times 90 \times 18$-t2N90A0.4FR & 303.8 & 88.8 & 18.7 & 1.96 & 1053.2 & 10.6 & 10.7 & 10.8 & 10.9 \\
\hline $302 \times 90 \times 18$-t2N90A0.6FR & 303.8 & 88.8 & 18.7 & 1.96 & 1054.2 & 8.6 & 8.9 & 9.1 & 9.3 \\
\hline $302 \times 90 \times 18$-t2N90A0.8FR & 303.8 & 88.8 & 18.7 & 1.96 & 1055.2 & 6.2 & 6.8 & 7.4 & 7.6 \\
\hline $202 \times 65 \times 13-\mathrm{t} 1.4 \mathrm{~N} 32.5 \mathrm{~A} 0-\mathrm{FX}$ & 202.5 & 63.6 & 16.0 & 1.40 & 678.3 & 10.5 & 10.5 & 10.5 & 10.5 \\
\hline $202 \times 65 \times 13-\mathrm{t} 1.4 \mathrm{~N} 32.5 \mathrm{~A} 0.2-\mathrm{FX}$ & 202.5 & 63.6 & 16.0 & 1.40 & 678.3 & 10.0 & 10.0 & 10.0 & 10.2 \\
\hline $202 \times 65 \times 13-\mathrm{t} 1.4 \mathrm{~N} 32.5 \mathrm{~A} 0.4-\mathrm{FX}$ & 202.5 & 63.6 & 16.0 & 1.40 & 678.3 & 8.6 & 9.0 & 9.2 & 9.5 \\
\hline $202 \times 65 \times 13-\mathrm{t} 1.4 \mathrm{~N} 32.5$ A0.6-FX & 202.5 & 63.6 & 16.0 & 1.40 & 678.3 & 7.1 & 7.7 & 8.2 & 8.7 \\
\hline $202 \times 65 \times 13-\mathrm{t} 1.4 \mathrm{~N} 32.5 \mathrm{~A} 0.8-\mathrm{FX}$ & 202.5 & 63.6 & 16.0 & 1.40 & 678.3 & 5.1 & 6.3 & 7.1 & 7.9 \\
\hline $202 \times 65 \times 13-\mathrm{t} 1.4 \mathrm{~N} 65 \mathrm{AO}-\mathrm{FX}$ & 202.5 & 64.0 & 17.5 & 1.44 & 701.0 & 11.9 & 11.9 & 11.9 & 11.9 \\
\hline $202 \times 65 \times 13-\mathrm{t} 1.4 \mathrm{~N} 65 \mathrm{A0} 0.2-\mathrm{FX}$ & 202.5 & 64.0 & 17.5 & 1.44 & 701.0 & 11.5 & 11.4 & 11.5 & 11.6 \\
\hline $202 \times 65 \times 13-\mathrm{t} 1.4 \mathrm{~N} 65$ A0.4-FX & 202.5 & 64.0 & 17.5 & 1.44 & 702.0 & 10.0 & 10.3 & 10.5 & 10.8 \\
\hline $202 \times 65 \times 13-\mathrm{t} 1.4$ N65A0.6-FX & 202.5 & 64.0 & 17.5 & 1.44 & 703.0 & 8.2 & 8.9 & 9.5 & 10.0 \\
\hline $202 \times 65 \times 13-\mathrm{t} 1.4 \mathrm{~N} 65 \mathrm{~A} 0.8-\mathrm{FX}$ & 202.5 & 64.0 & 17.5 & 1.44 & 704.0 & 6.2 & 7.4 & 8.3 & 9.1 \\
\hline $302 \times 90 \times 18-\mathrm{t} 2 \mathrm{~N} 44 \mathrm{~A} 0-\mathrm{FX}$ & 304.0 & 87.9 & 18.0 & 1.93 & 997.9 & 18.6 & 18.6 & 18.6 & 18.6 \\
\hline $302 \times 90 \times 18$-t2N44A0.2-FX & 304.0 & 87.9 & 18.0 & 1.93 & 998.9 & 17.8 & 17.8 & 17.9 & 18.1 \\
\hline $302 \times 90 \times 18-\mathrm{t} 2 \mathrm{~N} 44 \mathrm{A0} .4-\mathrm{FX}$ & 304.0 & 87.9 & 18.0 & 1.93 & 999.9 & 15.6 & 16.1 & 16.5 & 17.0 \\
\hline $302 \times 90 \times 18-\mathrm{t} 2 \mathrm{~N} 44 \mathrm{~A} 0.6-\mathrm{FX}$ & 304.0 & 87.9 & 18.0 & 1.93 & 1000.9 & 12.9 & 14.1 & 15.0 & 15.8 \\
\hline $302 \times 90 \times 18$-t2N44A0.8-FX & 304.0 & 87.9 & 18.0 & 1.93 & 1001.9 & 9.0 & 11.5 & 13.1 & 14.5 \\
\hline $302 \times 90 \times 18-t 2 N 90 A 0-F X$ & 303.9 & 88.8 & 18.7 & 1.96 & 1051.2 & 22.2 & 22.2 & 22.2 & 22.2 \\
\hline $302 \times 90 \times 18$-t2N90A0.2-FX & 303.9 & 88.8 & 18.7 & 1.96 & 1052.2 & 20.7 & 20.7 & 20.8 & 21.1 \\
\hline $302 \times 90 \times 18-\mathrm{t} 2 \mathrm{~N} 90 \mathrm{A0} .4-\mathrm{FX}$ & 303.9 & 88.8 & 18.7 & 1.96 & 1053.2 & 17.8 & 18.4 & 18.8 & 19.4 \\
\hline $302 \times 90 \times 18-t 2$ N90A0.6-FX & 303.9 & 88.8 & 18.7 & 1.96 & 1054.2 & 14.5 & 15.9 & 16.9 & 17.8 \\
\hline $302 \times 90 \times 18$-t2N90A0.8-FX & 303.9 & 88.8 & 18.7 & 1.96 & 1055.2 & 10.9 & 13.2 & 14.9 & 16.4 \\
\hline
\end{tabular}

a

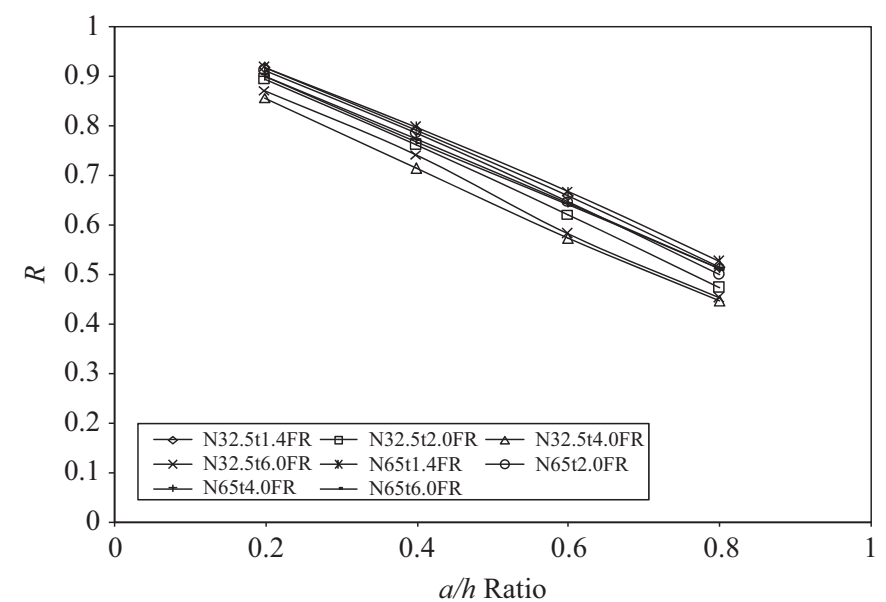

b

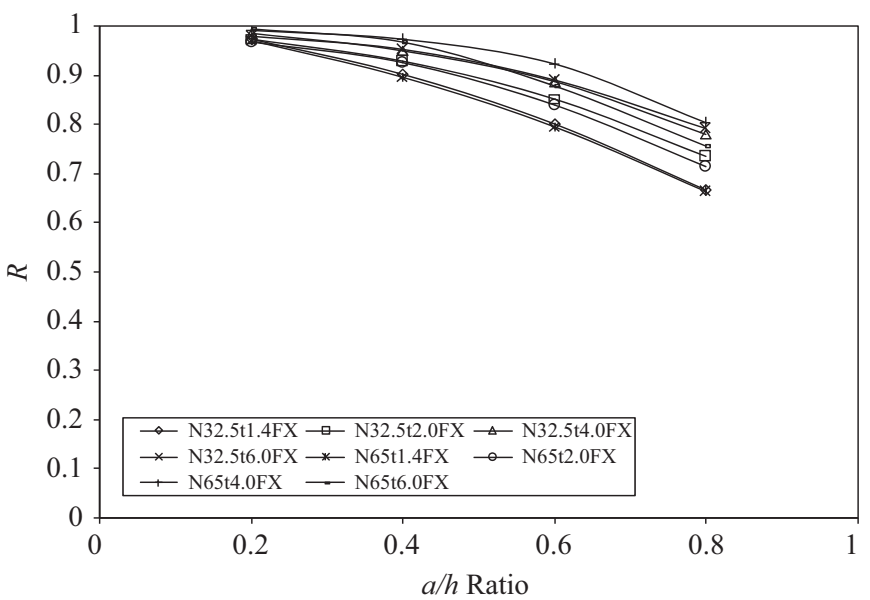

Fig. 9. Variation in reduction factors with sizes of holes diameter ratio for C202 section: (a) flanges unfastened condition and (b) flanges fastened condition.

Tables 1, 2, 6 and 7, it can be seen that, as expected, the failure load decreases as the size of the web holes increases and the failure load increases as the distance of the web holes increases.
For each series of specimens, the web crippling strengths of the sections without the web holes were obtained. Thus, the ratio of the web crippling strengths for sections with the web holes 
a

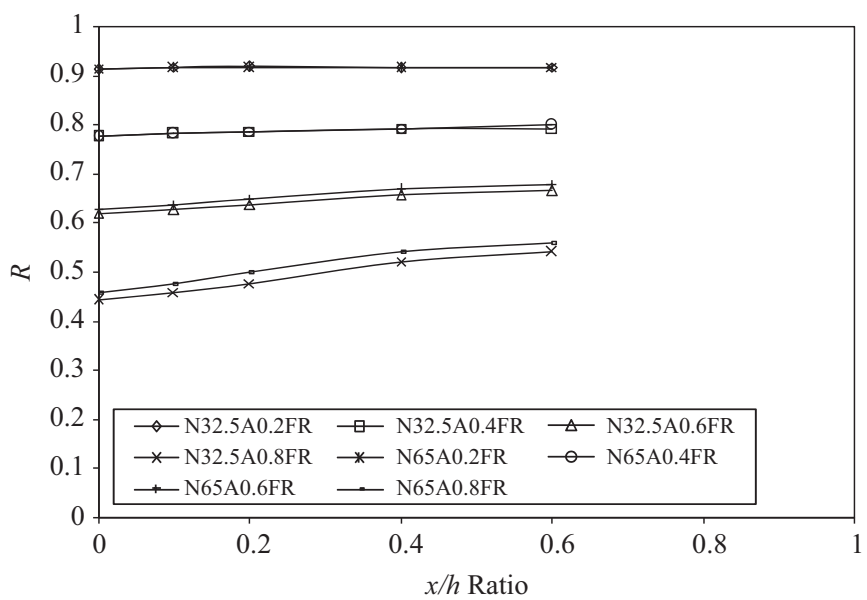

b

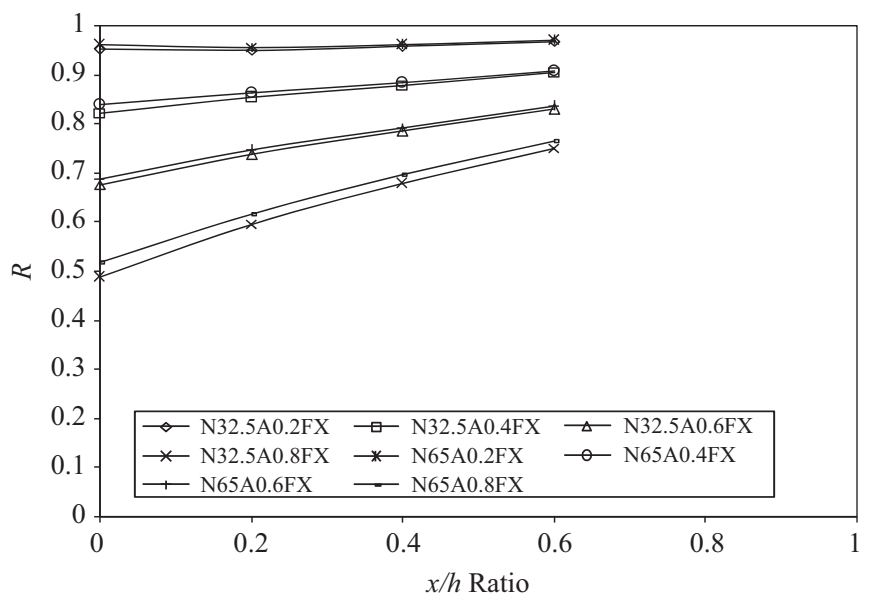

Fig. 10. Variation in reduction factors with holes position ratio for $\mathrm{C} 202$ sections: (a) flanges unfastened condition and (b) flanges fastened condition.

Table 8

Statistical analysis for the comparison of the strength reduction factor for flanges unfastened condition.

\begin{tabular}{ll}
\hline Statistical parameters & $R$ (Test \& FEA $) / R_{p}(1.04-0.68(a / h)+0.023(x / h))$ \\
\hline Mean, $P_{m}$ & 1.00 \\
Coefficient of variation, $V_{p}$ & 0.04 \\
Reliability index, $\beta$ & 2.83 \\
Resistance factor, $\phi$ & 0.85 \\
\hline
\end{tabular}

Table 9

Statistical analysis for the comparison of the strength reduction factor for flanges fastened condition.

\begin{tabular}{ll}
\hline Statistical parameters & $R($ Test \& FEA $) / R_{p}(1.00-0.45(a / h)+0.09(x / h))$ \\
\hline Mean, $P_{m}$ & 1.02 \\
Coefficient of variation, $V_{p}$ & 0.07 \\
Reliability index, $\beta$ & 2.81 \\
Resistance factor, $\phi$ & 0.85 \\
\hline
\end{tabular}

divided by the sections without the web holes, which is the strength reduction factor $(R)$, was used to quantify the degrading influence of the web holes on the web crippling strengths under the interior-two-flange loading condition. Evaluation of the experimental and the numerical results shows that the ratios $a / h$ and $x / h$ are the primary parameters influencing the web crippling behaviour of the sections with web holes. Therefore, based on both the experimental and the numerical results obtained from this study, two strength reduction factors $\left(R_{p}\right)$ are proposed using bivariate linear regression analysis for the interior-two-flange loading condition.

For the flanges unfastened condition,

$R_{P}=1.04-0.68\left(\frac{a}{h}\right)+0.023\left(\frac{x}{h}\right) \leq 1$

For the flanges fastened condition,

$R_{P}=1.00-0.45\left(\frac{a}{h}\right)+0.09\left(\frac{x}{h}\right) \leq 1$

The limits for the reduction factor Eqs. (1) and (2) are $h / t \leq 156, N / t \leq 84, N / h \leq 0.63, a / h \leq 0.8$, and $\theta=90^{\circ}$.

\section{Comparison of the experiment and numerical results with the proposed reduction factor}

The values of the strength reduction factor $(R)$ obtained from the experimental and the numerical results are compared with the values of the proposed strength reduction factor $\left(R_{p}\right)$ calculated using Eqs. (1) and (2), as plotted against the ratios $a / h$ and $h / t$ in Figs. 11 and 12, respectively. Tables 8 and 9 summarises a statistical analysis to define the accuracy of the proposed design equations. The values of the proposed reduction factor are generally conservative and agree well with the experimental and the numerical results for ITF loading conditions. As can be seen, the proposed reduction factor are generally conservative
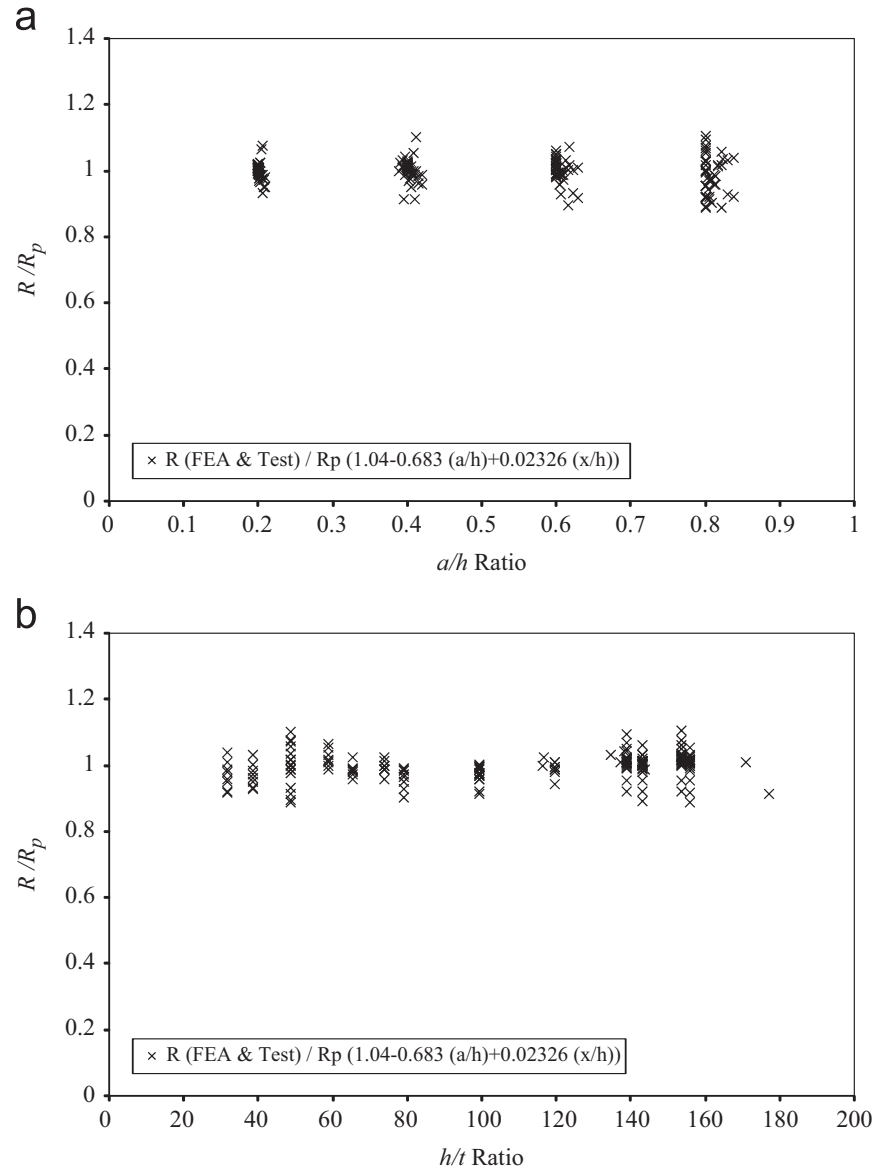

Fig. 11. Comparison of the strength reduction factor for the flanges unfastened condition. 

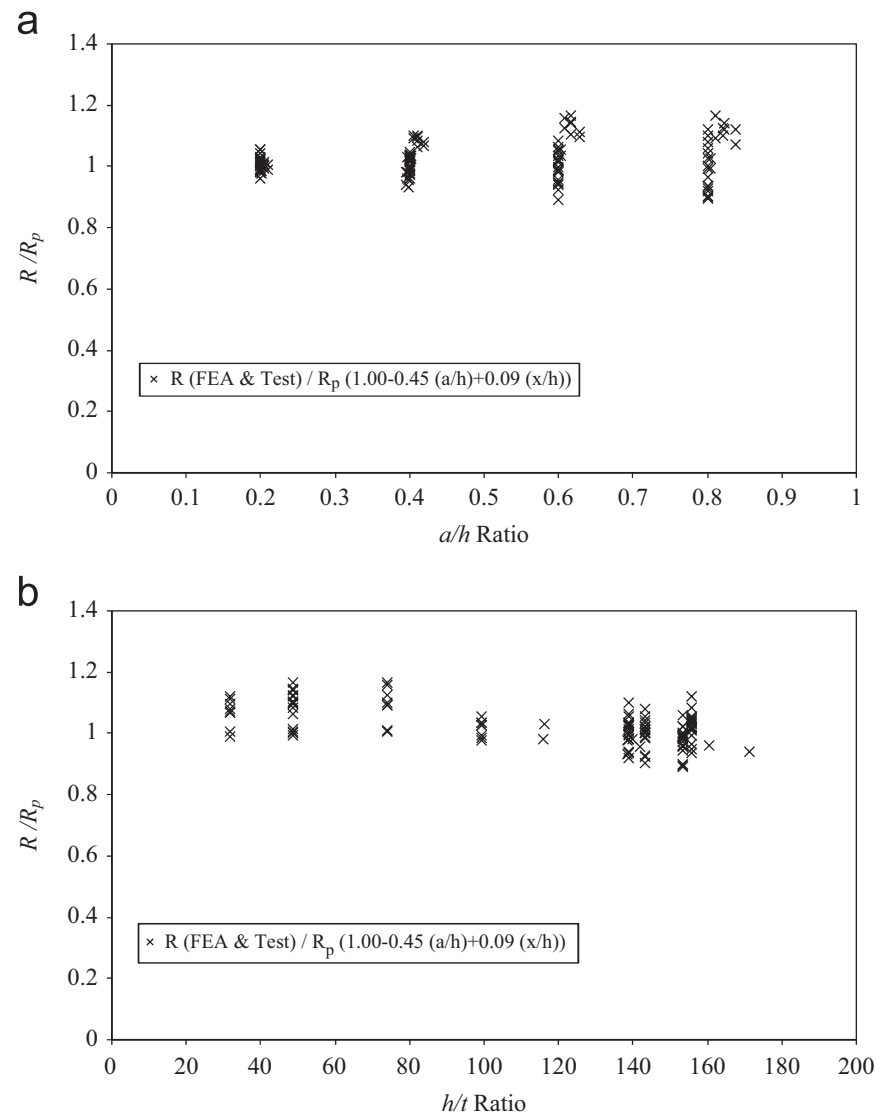

Fig. 12. Comparison of the strength reduction factor for the flanges fastened condition.

and agree with the experiment and the numerical results for both load cases. The mean value of the web crippling reduction factor ratio are 1.00 and 1.02 with the corresponding COV of 0.04 and 0.07 , and reliability index $(\beta)$ of 2.83 and 2.81 for the flanges are unfastened and fastened conditions, respectively. Thus, the proposed strength reduction factor equations are able to predict the influence of the web holes on the web crippling strengths of channel sections for the ITF loading condition.

\section{Conclusions}

The experimental and the numerical investigations of lipped channel sections with circular web holes subjected to web crippling have been presented. A series of tests was conducted on lipped channel sections with web holes subjected to the interior-two-flange (ITF) loading condition. The web slenderness value of the specimens ranged from 31.8 to 176.9. The diameter of the web holes was varied in order to investigate the influence of the web holes on the web crippling strength. The cases of the flanges of the channel sections being fastened and unfastened to the bearing plates also considered.

A finite element model that incorporated the geometric and the material nonlinearities has been developed and verified against the experimental results. The finite element model was shown to be able to closely predict the web crippling behaviour of the channel sections, both with and without circular web holes. Thereafter, a parametric study was carried out to study the effects of the different sizes of the cross-sections and the web hole on the web crippling strengths of the channel sections. It is shown that the ratios $a / h$ and $x / h$ are the primary parametric relationships influencing the web crippling behaviour of the sections with the web holes.

Web crippling strength reduction factor equations were proposed for the ITF loading conditions for both the cases of flanges unfastened and fastened to the support. It is shown that the proposed strength reduction factors are generally conservative and agree well with the experimental and the numerical results.

\section{Acknowledgements}

The authors gratefully acknowledge the help given by Metsec Plc, UK, in supplying the materials. The authors also wish to thank Mr. Chris Cameron and Mr. Andrew Crockett for their assistance in preparing the specimens and carrying out the experimental testing.

\section{References}

[1] Rhodes J, Nash D. An investigation of web crushing behaviour in thin-walled beams. Thin-Walled Structures 1998;32:207-30.

[2] Yu WW, Davis CS. Cold-formed steel members with perforated elements. Journal of the Structural Division 1973;99:2061-77.

[3] Sivakumaran KS, Zielonka KM. Web crippling strength of thin-walled steel members with web opening. Thin-Walled Structures 1989;8:295-319.

[4] LaBoube RA, Yu WW, Deshmukh SU, Uphoff CA. Crippling capacity of web elements with openings. Journal of Structural Engineering 1999;125:137-41.

[5] Langan JE, LaBoube RA, Yu WW. Structural behavior of perforated web elements of cold-formed steel flexural members subjected to web crippling and a combination of web crippling and bending. Final report, Civil Engineering Series 94-3, Cold-Formed Steel Series, Rolla, MO: University of MissouriRolla; 1994.

[6] Zhou F, Young B. Web crippling of aluminium tubes with perforated webs. Engineering Structures 2010;32:1397-410.

[7] NAS, North American Specification for the design of cold-formed steel structural members. AISI S100-2007, AISI Standard. American Iron and Steel Institute; 2007.

[8] ANSYS, User's manual, revision 11.0. Swanson Analysis System; 2011.

[9] EN, 10002-1: 2001. Tensile testing of metallic materials. Method of test at ambient temperature. British Standards Institution; 2001.

[10] ASCE, Minimum design loads for buildings and other structures. New York: American Society of Civil Engineers Standard; 2005. 